The INL is a

U.S. Department of Energy

National Laboratory

operated by

Battelle Energy Alliance

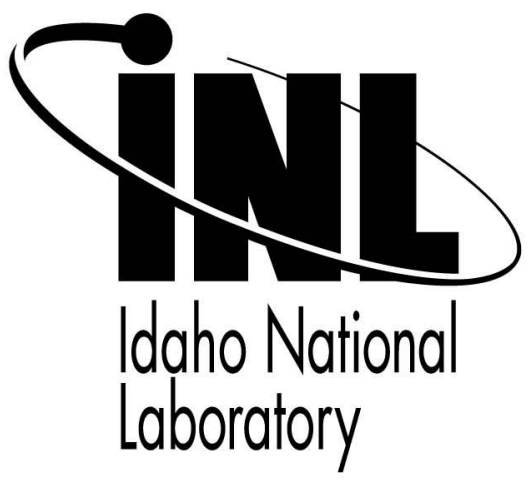

INL/CON-08-14209

PREPRINT

\title{
A Comparison of
} Neutron-Based NonDestructive Assessment Methods for Chemical Warfare Materiel and High Explosives

\section{CAARI}

\author{
E. H. Seabury \\ D. L. Chichester \\ C. J. Wharton \\ A. J. Caffrey
}

\section{August 2008}

This is a preprint of a paper intended for publication in a journal or proceedings. Since changes may be made before publication, this preprint should not be cited or reproduced without permission of the author. This document was prepared as an account of work sponsored by an agency of the United States Government. Neither the United States Government nor any agency thereof, or any of their employees, makes any warranty, expressed or implied, or assumes any legal liability or responsibility for any third party's use, or the results of such use, of any information, apparatus, product or process disclosed in this report, or represents that its use by such third party would not infringe privately owned rights. The views expressed in this paper are not necessarily those of the United States Government or the sponsoring agency. 


\title{
A Comparison of Neutron-Based Non-Destructive Assessment Methods for Chemical Warfare Materiel and High Explosives
}

\author{
E.H. Seabury, D.L. Chichester, C.J. Wharton, and A.J. Caffrey \\ Idaho National Laboratory, 2525 N. Fremont Avenue, Idaho Falls, Idaho 83415-3740
}

\begin{abstract}
Prompt Gamma Neutron Activation Analysis (PGNAA) systems employ neutrons as a probe to interrogate items, e.g. chemical warfare materiel-filled munitions. The choice of a neutron source in field-portable systems is determined by its ability to excite nuclei of interest, operational concerns such as radiological safety and ease-of-use, and cost. Idaho National Laboratory's PINS Chemical Assay System has traditionally used a ${ }^{252} \mathrm{Cf}$ isotopic neutron source, but recently a deuterium-tritium (DT) electronic neutron generator (ENG) has been tested as an alternate neutron source. This paper presents the results of using both of these neutron sources to interrogate chemical warfare materiel (CWM) and high explosive (HE) filled munitions.
\end{abstract}

Keywords: PGNAA, Electronic Neutron Generator.

PACS: 25.40.-h, 29 25.Dz

\section{INTRODUCTION}

In November 2007, two series of nonintrusive assessments were carried out at the Edgewood Area of the U.S. Army's Aberdeen Proving Ground (APG) using the Portable Isotopic Neutron Spectroscopy (PINS)[1] system. The PINS system is a prompt gamma-ray neutron activation analysis (PGNAA) system that is typically used in the identification of chemical warfare materiel (CWM) and high explosives (HE) in field-recovered munitions. The purpose of these tests was to compare the use of a deuteriumtritium electronic neutron generator (ENG) with ${ }^{252} \mathrm{Cf}$ as a neutron source in the identification of high explosives as well as in identifying and discriminating the riot control agents $\mathrm{CNS}, \mathrm{CNB}$ and the choking agent phosgene (CG).

The commercially-available PINS system consists of a high-purity germanium detector (HPGe), ${ }^{252} \mathrm{Cf}$ neutron source, moderator/shadow shield assembly, detector stand, multi-channel analyzer, and notebook computer. The data acquisition and online analysis software, PINS+, will analyze data concurrently with acquisition and display results to the user. This software will readily identify stockpile CWM such as the nerve agent sarin (GB), blister agents lewisite (L) and mustard gas (HD), as well as HE. Currently, PINS+ does not automatically identify the riot-control agents CNS and CNB or the choking agent CG. It is highly desirable for these agents to be identified by the software both for safety concerns in handling fieldrecovered munitions, as well as to ensure adherence to the Chemical Weapons Convention (CWC) in the handling, disposal, and accounting of these agents. The PINS system was tested using both the ${ }^{252} \mathrm{Cf}$ source as well as the DT ENG in order to determine which neutron source would provide better discrimination of the chemical agents and detection of HE.

\section{RIOT CONTROL AGENTS AND PHOSGENE}

The riot-control agent CNB consists of chloroacetophenone (mace), carbon tetrachloride, and benzene. CNS consists of chloroacetophenone, chloroform, and chloropicrin. CG has the chemical formula $\mathrm{COCl}_{2}$. The elemental weight percents of these agents are shown in table 1 . The discrimination of these three agents, which consist largely of the same elements, relies on neutron excitation of hydrogen, chlorine, oxygen, carbon and detection of the subsequent gamma rays. Carbon and oxygen are only readily excited by inelastic neutron scattering, requiring neutron energies of 4.4 and $6.13 \mathrm{MeV}$ respectively. Hydrogen is excited by thermal neutron 
capture, and chlorine is readily excited by both thermal neutron capture and inelastic neutron scattering.

TABLE 1. Elemental Composition of Riot Control Agents \& Phosgene.

\begin{tabular}{lccc}
\multicolumn{1}{c}{ Agent } & CNS & CNB & CG \\
\hline Density $\left(\mathrm{g} / \mathrm{cm}^{3}\right)$ & 1.47 & 1.14 & 1.37 \\
\hline Hydrogen Weight \% & 1.3 & 2.9 & -- \\
Carbon Weight \% & 19.6 & 39.5 & 12.1 \\
Nitrogen Weight \% & 3.4 & -- & -- \\
Oxygen Weight \% & 13.6 & 3.0 & 54.6 \\
Chlorine Weight \% & 62.1 & 54.6 & 71.7 \\
\hline
\end{tabular}

The riot-control agents were contained in 4.2-inch mortar projectiles that were overpacked into singleround-containers (SRCs). There were a total of three CNS and CNB samples each. The phosgene was contained in an overpacked 4.2-inch mortar projectile and an overpacked $75-\mathrm{mm}$ artillery projectile. The experimental arrangements of the two neutron sources are shown in figures 1 and 2. The ENG was operated in continuous ouput at voltage and current settings that would yield a total of $1.0 \mathrm{E}+07$ neutrons/second. The ${ }^{252} \mathrm{Cf}$ source emitted approximately $2.0 \mathrm{E}+07$ neutrons/second. The test items were radiographed prior to assessment in order to determine where the center of the mass of the chemical fill was on each item, in order to align them with the source and detector. Gamma ray spectra were recorded for a total of 3,000 live seconds on each sample for ${ }^{252} \mathrm{Cf}$ and 2,000 live seconds for the neutron generator. A 1,000 second background measurement was conducted with each neutron source and no test item present. Gammaray peak areas after background subtraction were extracted from the spectra for the elements chlorine, hydrogen, carbon, nitrogen, and oxygen. Ratios of peak areas are shown in Table 2.

TABLE 2. Peak Area Ratios of Riot Control Agents \& Phosgene.

\begin{tabular}{lcccc}
\hline Agent & $\begin{array}{c}\text { Cl 1165/ } \\
\text { Cl 1763 } \\
\text { (Cf) }\end{array}$ & $\begin{array}{c}\text { H 2223/ } \\
\text { Cl 1165 } \\
\text { (Cf) }\end{array}$ & $\begin{array}{c}\text { Cl 1165/ } \\
\text { Cl 1763 } \\
\text { (ENG) }\end{array}$ & $\begin{array}{c}\text { O 6129/ } \\
\text { Cl 1763 } \\
\text { (ENG) }\end{array}$ \\
\hline CNB 1 & $24.6 \pm$ & $0.11 \pm$ & $2.15 \pm$ & $0.36 \pm 12$ \\
& 1.5 & 0.007 & 0.56 & \\
\hline CNB 2 & $27.3 \pm$ & $0.12 \pm$ & $1.76 \pm$ & $0.36 \pm$ \\
& 1.6 & 0.008 & 0.41 & 0.08 \\
CNB 3 & $26.3 \pm$ & $0.14 \pm$ & $2.76 \pm$ & $1.29 \pm$ \\
& 1.7 & 0.008 & 0.71 & 0.26 \\
CNS 1 & $8.2 \pm 0.7$ & $0.062 \pm$ & $0.74 \pm$ & $0.48 \pm$ \\
& & 0.002 & 0.24 & 0.07 \\
CNS 2 & $7.1 \pm 0.5$ & $0.095 \pm$ & $0.47 \pm$ & $0.43 \pm$ \\
& & 0.009 & 0.17 & 0.05 \\
CNS 3 & $6.3 \pm 0.5$ & $0.063 \pm$ & $0.92 \pm$ & $1.05 \pm$ \\
& & 0.006 & 0.33 & 0.14 \\
CG 1 & $3.3 \pm 0.3$ & $0.14 \pm$ & $0.16 \pm$ & $0.26 \pm$ \\
(4.2) & & 0.099 & 0.10 & 0.04 \\
CG 2 & $6.1 \pm 0.6$ & $0.28 \pm$ & $0.89 \pm$ & $0.79 \pm$ \\
(75) & & 0.039 & 0.58 & 0.34 \\
\hline
\end{tabular}

FIGURE 1. PINS ${ }^{252} \mathrm{Cf}$ experimental arrangement..

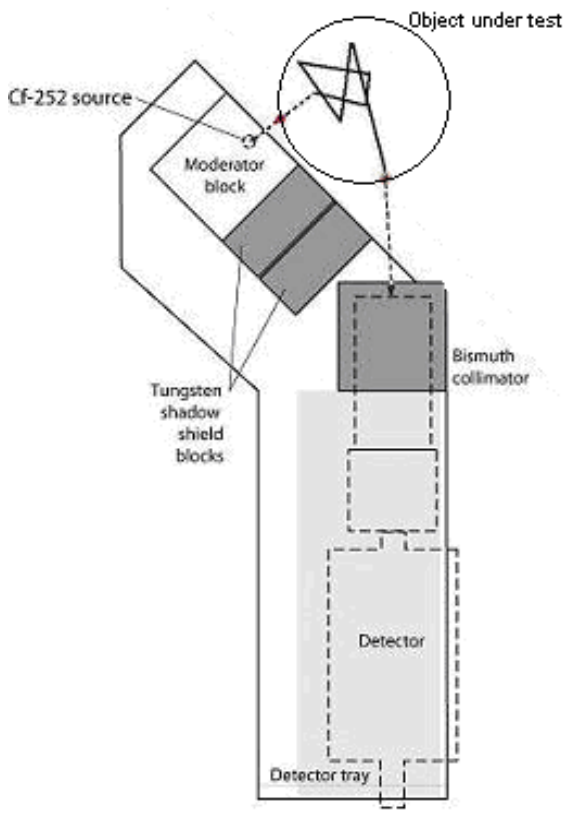

FIGURE 2. PINS DT generator experimental arrangement.

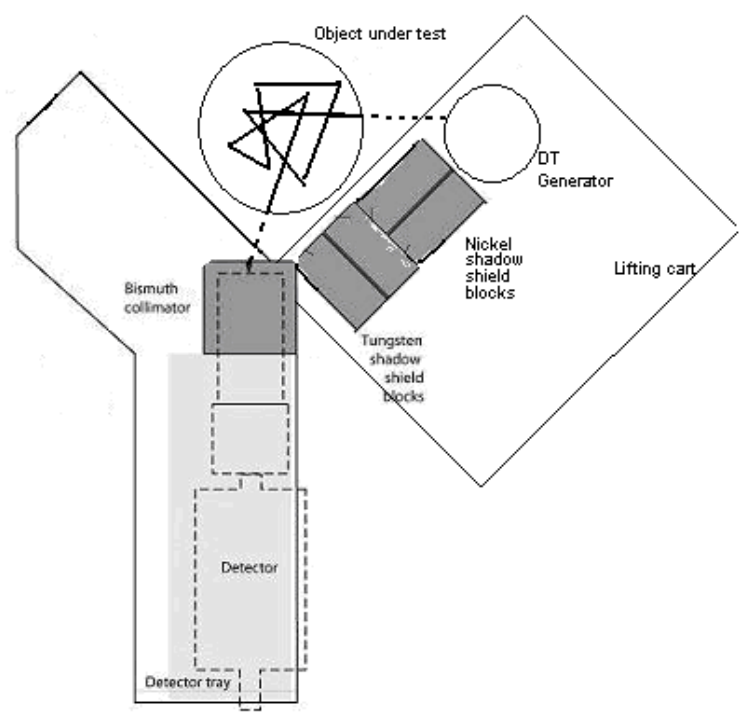

As can be seen in the table, the agent $\mathrm{CNB}$ can be readily distinguished from both CNS and CG by the ratio of the $1763 \mathrm{keV}$ chlorine inelastic scattering peak to the $1165 \mathrm{keV}$ thermal capture peak for both the ${ }^{252} \mathrm{Cf}$ source and the neutron generator. This is consistent with the relative hydrogen content of CNB compared with the two other agents. The agents CNS and $\mathrm{CG}$ can be distinguished from one another by the ratio of the hydrogen $2223 \mathrm{keV}$ to chlorine $1165 \mathrm{keV}$ thermal capture peaks when the ${ }^{252} \mathrm{Cf}$ source is used. The neutron generator provided very low count rates after background subtraction for hydrogen and carbon, 
with values statistically equivalent to zero. There were however significant net oxygen peak counts, and the ratio of the oxygen $6129 \mathrm{keV}$ inelastic scattering peak to the $1763 \mathrm{keV}$ chlorine inelastic scattering peak can also be seen in table 2 .

It was anticipated that the $14.1 \mathrm{MeV}$ neutron source would provide additional discrimination between $\mathrm{CG}$ and the other fills, with enhanced excitation of the oxygen $6129 \mathrm{keV}$ and carbon $4439 \mathrm{keV}$ inelastic scattering peaks, but this was found not to be the case. There is a high degree of variance in the oxygen to chlorine ratio among measurements of a single chemical. This is likely due to the effects of subtracting the high background oxygen counts from the test item spectra. This background is from the materials surrounding the test item, including the concrete pad on which the measurements took place.

\section{HIGH EXPLOSIVES}

The experimental arrangements for the high explosives measurements were identical to those of the riot-control agents. The test items were a $155-\mathrm{mm}$ artillery projectile filled with $15 \mathrm{lbs}$. Composition B and an 81-mm mortar projectile filled with $2.2 \mathrm{lbs}$ Composition C-4. The munitions were assayed bare, overpacked, with a polyethylene annulus surrounding them, and overpacked with an annulus around the overpack.. Again, background measurements were performed for 1,000 live seconds with each neutron source and spectra were recorded for 2,000 live seconds. The PINS system currently relies on the detection of nitrogen thermal capture peaks for the identification of explosives. Gamma-ray peak areas for nitrogen thermal capture peaks are shown in Table 3.

As can be seen in the table, the ${ }^{252} \mathrm{Cf}$ source provides greater nitrogen thermal capture peak counts than the neutron generator, even when a moderator is used around the munition. However, nitrogen has strong inelastic scattering peaks at 1635, 2313, and $5105 \mathrm{keV}$.[3] The $5105 \mathrm{keV}$ peak is contaminated with the second escape peak from inelastic excitation of oxygen. The $2313 \mathrm{keV}$ peak was observed in all of the spectra with the exception of the overpacked 155$\mathrm{mm}$ Comp. B munition, both with and without an annulus. These peak areas are shown in Table 4.

These peak areas indicate that should the analysis algorithm be modified to identify the nitrogen inelastic scattering peaks, the identification of explosives by the software would still occur, although the time to identify would be longer than with the ${ }^{252} \mathrm{Cf}$ source, with overpacked items requiring additional assay times.

\section{SUMMARY}

The DT neutron generator did not provide enhanced identification or discrimination of the riot control agents and phosgene. The agent CNB could be distinguished from CNS and CG with the neutron generator source, but $\mathrm{CNG}$ could not be distinguished from CG. Future tests could include the addition of moderation around the neutron generator in order to enhance the production of gamma rays from thermal neutron capture, allowing greater reliance on the hydrogen thermal capture peak in agent identification.

The detection of high explosives with the neutron generator was poor when compared with the ${ }^{252} \mathrm{Cf}$ source when nitrogen detection was based on the thermal neutron capture peaks, even when a polyethylene annulus was used. The performance was enhanced significantly when nitrogen detection was based on detection of the $2313 \mathrm{keV}$ nitrogen inelastic scattering peak, rather than on the thermal capture peaks

TABLE 3. Nitrogen $10,829 \mathrm{keV}$ Peak Areas for Explosives per 1000 Live Seconds

\begin{tabular}{|c|c|c|c|c|c|c|c|c|}
\hline Explosive & \multicolumn{2}{|c|}{ Bare } & \multicolumn{2}{|c|}{ w/Annulus } & \multicolumn{2}{|c|}{ Overpacked } & \multicolumn{2}{|c|}{ Overpacked w/Annulus } \\
\hline Neutron Source & ${ }^{252} \mathrm{Cf}$ & DT & ${ }^{252} \mathrm{Cf}$ & DT & ${ }^{252} \mathrm{Cf}$ & DT & ${ }^{252} \mathrm{Cf}$ & DT \\
\hline C-4 & $32 \pm 4$ & $14 \pm 8$ & $65 \pm 6$ & $12 \pm 16$ & $29 \pm 5$ & $3 \pm 8$ & $61 \pm 9$ & $16 \pm 12$ \\
\hline Comp. B & $61 \pm 9$ & $16 \pm 9$ & $90 \pm 8$ & $38 \pm 10$ & $62 \pm 6$ & $26 \pm 9$ & $79 \pm 10$ & $1 \pm 10$ \\
\hline
\end{tabular}

TABLE 4. Nitrogen 2,313 keV Net Peak Areas for Explosives per 1000 Live Seconds for Neutron Generator Spectra

\begin{tabular}{lcccc}
\hline \multicolumn{1}{c}{ Explosive } & Bare & Overpacked & w/Annulus & Overpacked w/Annulus \\
C-4 & $292 \pm 61$ & $272 \pm 53$ & $486 \pm 70$ & $178 \pm 79$ \\
Comp. B & $243 \pm 68$ & -- & $502 \pm 76$ & -- \\
\end{tabular}




\section{REFERENCES}

1. A.L. Siedenstang et al., "PINS Chemical Assay System User's Manual”, Idaho National Laboratory, 2004.

2. J.A.F. Compton, Military Chemical and Biological Agents Chemical and Toxicological Properties, Caldwell NJ:Telford Press, 1987, pp. 220-231.

3. A. M. Demidov et al., Atlas of Gamma-Ray Spectra from Inelastic Scattering of Reactor Fast Neutrons, Moscow:Atomizdat, 1978, pp. 34-35., 